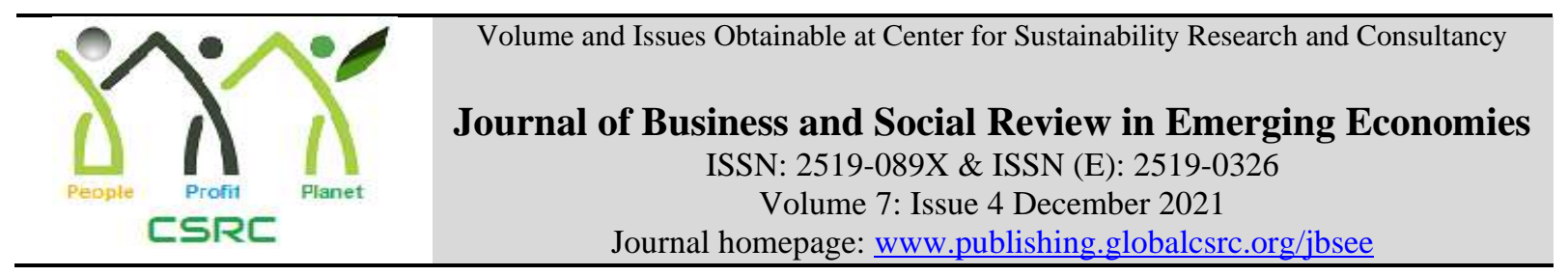

\title{
Relationship between Representation of Violence Against Women in TV Drama Serials and Reactivity of Viewers
}

Sajida Awais, Faculty of Media and Communication, University of Central Punjab, Lahore, Pakistan

*Atif Ashraf, Faculty of Media and Communication, University of Central Punjab, Lahore, Pakistan

Ghulam Shabir, Faculty of Media and Communication, University of Central Punjab, Lahore, Pakistan

*Corresponding author's email: atifashraf@ucp.edu.pk

\begin{tabular}{l}
\hline ARTICLE DETAILS \\
\hline History \\
Revised format: Nov 2021 \\
Available Online: Dec 2021 \\
\hline Keywords \\
Viewer's Reactivity, \\
Perception of Violence \\
against Women, Gender \\
Differences
\end{tabular}

\section{JEL Classification}

$M 1, M 2$

\section{OPEN ACCESS}

\begin{abstract}
Purpose: The present study aims to explore the role of viewer's reactivity of entertainment and empathy in their perception of violence against women among viewers of Lahore, Pakistan. The supplementary aim was also formulated to gain more clear insight which is the role of viewers' gender in viewer's reactivity and perception of violence against women.

\section{Design/Methodology/Approach}

Quantitative method was used in the study. Sample was consisted of 500 viewers of the thirty dramas serials of Geo, ARY Digital and Hum TV which presented violence against women. The participants were drawn through purposive and snowball sampling strategies. The sample has 233 male participants and 267 female participants.
\end{abstract}

Findings: The findings indicated that viewer's reactivity of both enjoyment and empathy correlated with perception of violence against women. Gender differences were found only for the one sub scale of perception (i.e., domination).

Implications/Originality/Value: The findings highlighted that perception of violence against women was more inclined towards active violence being portrayed by the entertainment channels and chances to imitate the same behavior in society cannot be ruled out.

(C) 2021 The authors, under a Creative Commons AttributionNonCommercial 4.0

Recommended citation: Awais, S., Ashraf, A and Shabir, G. (2021). Relationship between Representation of Violence Against Women in TV Drama Serials and Reactivity of Viewers. Journal of Business and Social Review in Emerging Economies, 7 (4), 821-833.

\section{Introduction}

Violence, in the world report, has been categories as self-directed, interpersonal, and collective violence. Violence against women and girls (VAWG) or Gender-based violence (GBV) affects 1 in 3 women in their lifetime and is a global pandemic (World Bank, 2019). Violence against women is the main obstacle to attain human rights by women. Violence against women and children is "any action or violation carried out by people harming another's life, physical or psychological dignity or rights, and negatively affecting his or her personality's development" 
(Council of Europe, 2001). Media can play a significant role in either perpetuating or challenging social norms and behaviors that condone violence against women. Over the past 40 years, there has been a drastic increase in television scenes that include acts of violence against women as fundamental subplots in television (Jamieson, \& Romer, 2014). Violence in modern film and television is almost hard to escape; what was once seldom represented on television is now a prevalent plotline (Cuklanz, 2000; Lee, Hust, Zhang, \& Zhang, 2011). Therefore, the present research aimed to examine the role of viewer's reactivity towards drama scenes presenting violence against women in their perception of violence against women in real life.

Violence against women is a continuing societal problem that impacts one in three women around the world. Factors associated with violence against women can be identified at different levels- individual, family, community, and social. In a recent report of WHO (2021) violence against women is a major health problem and violation of human rights of women. An estimated $30 \%$ of women population worldwide experience intimate partner of non-partner violence. More precisely, about $27 \%$ of them have been experiencing violence by intimate partner. Considering the importance of this problem, United Nations presented a resolution on the Eradication of Violence towards women (DEVAW) in 1993 and international day for the elimination of violence against women is celebrated on 25 November. However, violence against women still persist (Bloom, 2008).

Difference in socialization process of gender role, its stereotypes as well as the consequences of these stereotypes relate to the others as well as to the environment in term of their capacity. Environment taught the females to think about the emotions of other by putting themselves in other's shoe. On contrary, it taught the males to be expressive even about the expression of hostility and anger (Díaz-Aguado, 2003). These elements provided a baseline for the assembly of gender violence (Mahlstedt \& Welsh, 2005; Murnen, Wright, \& Kaluzny, 2002). Biologcally, both females and males were not predestined as victim or agressors and born without any biases. However, the stereotypes associated with their roles developed from cultural and environment which reinforce the stereotypical behavior related to gender role and thus legitimize gender violence (White, 2001) which is mostly occur in close relationships. Accordingly, it can be said that socialization is a crucial aspect to establish gender roles along with the formation of gender parity (Expósito \& Moya, 2005; Pratto \& Walker, 2004). Gender parity with the support of cultural values legalized the domination of the strong and subordination of the weak which is an important aspect of violence.

In the present age, almost every home of Pakistan has a television (Hafeez, Ahmed, Khan \& Safdar , 2020) which is a source of entertainment. In some serials, there are progressive and gender-sensitive messages, and in most of them patriarchal values are reinforced and orthodoxy is denounced (Safdar \& Khan, 2020) which may affect societal norms and values (Wear \& Skillicorn, 2009). This increase in access to media, as well as, the prevalence of violence in media further intensifies the need for studies to address the representation of violence against women in the Pakistani media. International literature although existed on the representation of violence against women on TV, however, Pakistani literature falls short in this regard.

In Pakistan, approximately 70-90\% of the women experience domestic violence (Human Rights Watch, 1999) which is a leading cause of violence against women worldwide. Domestic violence in Pakistan is taken as private matter and therefore not much attention is placed on it on policy making level (Fikree, \& Bhatti, 1999). The reason of this discrimination is the established societal norms (Bettencourt, 2000) which lead to physical, psychological and emotional abuse (Human Rights Commission of Pakistan, 2000). Figures indicated that only in the year 2020 around 1000 girls and women have been killed on the name of honour in the country (Shah, July 28, 2021).Several steps were taken to overthrow the violence against women in Pakistan such as formation of policies and laws for differenct types of violence. For instance, Women's Protection Bill, the Prevention of Anti-Women Practices Act, the Domestic Violence (Prevention and Protection) Act, Protection Against Harassment of Women at the Workplace Act, Acid and Burn Crime Bill, as well as amendment in the criminal law (Offences 
in the name or pretext of Honour) Act of 2016. However, implementations of these acts and policies were not without challenges.

Most often men believe that wife is docile and submissive which are subjected to control, discipline, and violent punishment (Zakar, Zakar, \& Kraemer, 2013). She deserves "stern warning" or "symbolic humiliation" to show disapproval or anger) if she refuses sex, shows negligence in the appropriate care of children, or if she is sexually unfaithful (Abraham, 2000; Ayyub, 2000; Fikree, Razzak \& Durocher, 2005). However, women with higher educational levels than their husbands are less likely to suffer beating and intimidation (Jejeebhoy, 1998; Visaria, 1999).

Social perception of violence against women has been explored earlier by Expósito and Herrera (2009). This study was conducted to explore the social perception of people about gender violence by gathering gender profiles of women victims who faced abuse and the men perpetrator who performed violence against women by collecting data about both the individual and the social factors (self-esteem and power in relationship respectively) related to violence against women. Findings highlighted that perpetrator and victim both possess specific social profile related to both the individual and the social factors.

El Abani and Pourmehdi (2017) explored the perception of domestic violence against women among Libyan migrants. They found that Libyan migrants perceive threat to use violence, verbal abuse, physical/sexual violence and economic abuse all are the forms of domestic violence against women. Moreover, ninety five percent that husband's aggressive acts, shouting, pushing, punching and breaking things are the act of domestic violence against women. Another study related to domestic violence against women in European Union also found the similar results about perception of domestic violence against women. Around $78 \%$ Europeans recognized domestic violence against women and this ratio was 74\% in 2016. Moreover, $15 \%$ of the respondents think that domestic violence is a private and family matter (Eurobarometer, 2016).

Many researchers have also considered the impact of media on women specifically. Through the content in media, women are taught to 'self-silence' and to place their partners' needs above their own (Margolis, 1998). Similarly, women who consume media with violence may not perceive acts of violence as criminal victimization, while they are more likely to do so if they if the perpetrators 'deprive victims of liberty, threaten their lives or physical integrity, or produce psychological harm' (Lievore, 2003). The impact of violence against women in media on a global scale is an arena of particular concern since there is clear research evidence that television has the potential to shape viewers' opinions and behaviors (Kahlor \& Eastin, 2011). Moreover, Roshan and Parvez (2012) investigated the dramatized violence against women in PTV dramas on knowledge, attitude, and actual behavior. Data was collected from 532 students and analyzed through t-test and correlation. Gender differences were found and correlation between exposure of PTV dramas and youth knowledge of verbal violence as well as with youth attitude of verbal violence was also found.

\section{Problem Statement}

Pakistan ranked as the world's third last country from 156 of the ranked countries on gender parity (World economic forum, 2021). Women face a series of violent acts/threats ranging from crime, abduction, poor health care, honor killing, acid throwing, workplace harassment, and lower education. This present situation seems awful to Pakistani people. It is because of the societal norms that Pakistani society accepts that women face violence and discrimination on a daily basis (Bettencourt, 2000). In addition it has been found that film and television programs affect gender-stereotypes and attitudes toward violence (Flood \& Pease, 2009; Huesmann \& Kirwil, 2007). Media desensitize the magnitude of the problem (Strasburger \& Wilson, 2002), and attitudes towards violence against women (Emmers-Sommer, Pauley, Hanzal, \& Triplett, 2006; Lee, Lindsey, \& Kim, 2017; Wright \& Tokunaga, 2016). However, research focusing on opinion formation and perception as a reaction of mediated violence exposure are quite limited (Lievore, 2003). Moreover, such evident impacts of dramas on perception are scarce. One study explored the impact of PTV dramas on knowledge, attitude and actual behaviors (Roshan \& 
Parvez, 2012).

\section{Rationale}

Desensitization to violence is a growing problem of present time. A significant impact in the desensitization of women is that they become less likely to report violence and abuse by their partners as violent media teaches them that it is commonplace. This is especially prominent if the women are leading lives with traditional gender role attitudes as they are inhibited by stereotypical and narrow representations of violence in media that disable them from being able to recognize other types of violence that they are being subjected to (Harris, Firestone, \& Vega, 2005). Pakistani society is a bearer of patriarchy, however, with regards to Pakistan; limited studies were conducted addressing the specific representations of violence against women in media and its impacts. With regards to Pakistan, limited studies are addressing the specific representations of violence against women in mass media. Moreover, the amount of Pakistani literature on the subject of perception of violence against women is not representative of the magnitude of the problem and perception of violence against women may influences the actual behavior towards violence against women as indicated by literature. Therefore, the present study aimed to explore the role of viewer's reactivity and perception on the subject of violence against women.

It is quite true that being a woman lead an individual to face discrimination, however there are certain other factors that may facilitate violence against women. These included sexual identity, environment, skin colour, nationality, ethnicity etc. (Igareda, 2013). Considering this fact, sexual identity (gender) was explored in the present research due to their important role in the perception of violence against women.

\section{Objectives of the Study}

The following objective was considered to better understand the underlying characteristics of violent against women.

To examine the relation of viewer's reactivity with perception of violence against women.

To examine the gender differences about the viewer's reactivity and perception of violence against women.

\section{Hypotheses}

Viewer's reactivity is likely to relate with perception of violence against women in real life situations.

Female participants are more likely to perceive violence against women as an act of violence than male participants.

\section{Method}

\section{Research Design}

A cross-sectional design was used to assess the association of viewer's reactivity and perception of violence against women among general population of Lahore, Pakistan.

\section{Sampling Technique}

Both purposive and snowball sampling strategy was used to collect data. Some participants were initially selected based on being the regular viewers of the selected thirty dramas form Geo, HUM TV, and ARY Digital that presented violence against women using purposive sampling strategy. Then further participants were approached using snowball of the initial sample. Snowball sampling was used because the selected participant may have some other family members and friends that were regular viewers of dramas.

\section{Sample}

For the present research, 500 viewers of the thirty dramas presenting violence against women were taken from Lahore, Pakistan. The participants having a mean age of 20.95 ( $S D=3.57$ ). Details of sample characteristics are presented in Table 1. 
Table 1

Descriptive Statistics of Sample

\begin{tabular}{lllll}
\hline Variable & $N$ & $\%$ & $M$ & $S D$ \\
\hline Age (in years) & & & 20.95 & 3.57 \\
No. of dramas watches & & & 0.47 & 0.66 \\
Gender & 233 & 46.6 & \\
Male & 267 & 53.4 & \\
Female & & & \\
Area & 251 & 50.2 & \\
Rural & 249 & 49.8 & \\
Urban & & & \\
Education & 1 & 0.2 & \\
Matric & 249 & 49.8 & \\
Intermediate & 146 & 29.2 & \\
Graduation & 94 & 18.8 & \\
Post-graduation & 10 & 2.0 & \\
Any other & & & \\
\hline
\end{tabular}

The table showed that most of the participants were females which constitute $53.4 \%$ while the remaining $46.6 \%$ were male participants. An almost equal number of participants belong to rural $(50.2 \%)$ and urban areas $(49.8 \%)$ of Lahore. Most of the respondents having an intermediate degree $(n=249)$, followed by a graduation degree $(n=146)$, post-graduation $(\mathrm{n}=$ 94), any other degree (for instance MBBS $n=10$ ) while only one of them reported matriculation. Participants watched on an average 9 drama series among the 30 selected dramas.

\section{Instruments}

\section{Demographic Sheet}

The demographic sheet included information about the gender of the participants, their age, education, family income, and residential area to analyze few of them in the main analyses. For instance, gender of the participants was analyzed to see the possible gender differences.

\section{Viewers' Reactivity}

The reactivity of viewers to violent media segments was assessed based on (Fanti et al., 2009) which was adopted for the present research. The participants will complete four items on how "normal" they found the different violent scenes and four questions to measure their empathic responses with the victim of violence indicating the scenes as an act of violence. These items were initially adapted by Fanti et al. (2009) from the Film Evaluation Instrument and Victim Evaluation Instruments respectively (Linz, Donnerstein, \& Penrod, 1984), and were further adopted for the present study. The items tapped two of the subscales; enjoyment (considered as normal practice) and empathy (considered as an act of violence). Participants rated their responses using a scale ranging from 0 (strongly disagree) to 4 (strongly agree). Overall mean scores on four respective items of two subscales were computed and can be utilized further.

\section{Perception of violence against women}

Perception of participants about violence against women was measured using the Perceived 
Gender Violence scale (VGP; Spanish acronym) which is a modified version of the VEG scale (Cantera, Estébanez \& Vázquez, 2009; Estébanez \& Vázquez, 2010). This scale measures' perception of gender-based violence in real life and can be used for the perception of violence against men or women. This was a 47 items measure assessing ten subscales related to violence. In the present study, the adapted scale consisted of 20 items that tap six aspects of verbal violence. The aspects are as follows; control, discrediting, affective indifference, emotional manipulation, threat, and domination. Furthermore, three items related to physical violence were formulated and added for present research.

\section{Procedure}

Formal permission from authors of instruments was taken to use them for research as well as to translate them for local viewers. The translation was carried out using Mappi guidelines (Mapi Research Institute, 2002). The scales were adapted considering the cultural context of Pakistan and the items related to physical and verbal violence only. The items of sexual violence were excluded due to difficulty to gather this information from the general population. Then, piloting of the protocol was done to identify any issue in the measure's comprehension and to analyze psychometric properties. The piloting of protocol indicated that the font size of the protocol was relatively small and was changed to improve readability in the main study. Instruments were administered in a face-to-face manner. Consent for participation was taken and participants were also informed about confidentiality and the anonymity of data as well as about the objectives of the present study. Moreover, they were guided about their right to withdraw at any point they felt uncomfortable. If participants ask for an interpretation of any items on the surveys, administrators were instructed to respond, "Please use your best interpretation to answer all the items." However, clarifications may be made about the demographic information, if requested. For the less educated participants, the researchers administered the scales by asking them all of the questions. SPSS software version 23.00 was used to analyze the data.

\section{Results}

Before conducting the main analyses, descriptive and reliability analyses were computed to assess the mean, standard deviance, minimum, maximum and internal consistencies of the sub scales. Moreover, skewness and kurtosis were assessed to analyze the normality of distribution. Table 2 presented an overview of minimum, maximum, mean, standard deviation, Cronbach alpha reliabilities, skewness, and kurtosis of viewer's reactivity and perception of violence against women.

Table 2

Reliability, and Normality of Viewer's Reactivity and Perception of Violence against women $(\mathbf{N}=\mathbf{5 0 0})$

\begin{tabular}{|c|c|c|c|c|c|c|c|c|}
\hline Variables & $k$ & $\alpha$ & Skew & Kur & Min & Max & $M$ & $S D$ \\
\hline \multicolumn{9}{|l|}{ Viewer's reactivity } \\
\hline Entertainment & 4 & 0.77 & 0.67 & -0.21 & 0.00 & 4.00 & 1.26 & 1.01 \\
\hline Empathy & 4 & 0.80 & -0.46 & -0.54 & 0.00 & 4.00 & 2.60 & 1.07 \\
\hline \multicolumn{9}{|c|}{ Perception of Violence against Women } \\
\hline Control & 3 & 0.71 & 0.55 & -0.32 & 0.00 & 4.00 & 1.83 & 1.07 \\
\hline Discrediting & 5 & 0.77 & -0.84 & -0.37 & 0.60 & 4.00 & 2.98 & 0.95 \\
\hline Affective indifference & 3 & 0.77 & -1.04 & 0.03 & 0.00 & 4.00 & 2.98 & 1.12 \\
\hline Threats & 4 & 0.70 & -1.03 & 0.66 & 0.00 & 4.00 & 2.98 & 0.96 \\
\hline Emotional manipulation & 2 & 0.80 & -0.82 & -0.57 & 0.00 & 4.00 & 2.90 & 1.29 \\
\hline
\end{tabular}




$\begin{array}{lcccccccc}\text { Domination } & 2 & 0.87 & -0.94 & -0.47 & 0.00 & 4.00 & 2.96 & 1.31 \\ \text { Physical violence } & 3 & 0.85 & -1.09 & -0.02 & 0.00 & 4.00 & 3.07 & 1.15\end{array}$

Table 2 showed that the sub scales have minimally two items and maximally five items. Further, it showed that internal consistencies of all the sub-scales were good to average as it ranged between $\alpha=.70$ (threats) to $\alpha=.87$ (domination). Furthermore, skewness and kurtosis indicated normality of the data as all the values of skewness ranged between -1.09 to 0.67 while kurtosis ranged between -0.54 to 0.66 . Table further showed that the scores of all the sub scales ranged from 0 to 4 similar to the original rating anchors of the sub scales (except for the minimum value of discrediting). The mean scores of all of the subscales were above the midpoint of the ratings (i.e., 2.5) except entertainment and control.

After these preliminary analyses, Pearson product moment correlation was run to assess the association of viewer's reactivity with the perception of violence against women in real life. Table 3 presented the overview of the relationship between the sub scales of viewer's reactivity and the perception of violence against women.

Table 3

Pearson Product Moment Correlations of the Study Variables

\begin{tabular}{|c|c|c|c|c|c|c|c|c|}
\hline Variables & 2 & 3 & 4 & 5 & 6 & 7 & 8 & 9 \\
\hline 1. Entertainment & $.12 * *$ & $-.20 * * *$ & $-.14 * *$ & $-.19 * * *$ & $-.11 *$ & -.02 & .08 & -.01 \\
\hline 2. Empathy & - & -.01 & $.16^{* * *}$ & .06 & $.32 * * *$ & $.33 * * *$ & $.26 * * *$ & $.20 * * *$ \\
\hline 3. Control & & - & $.45 * * *$ & $.50 * * *$ & $.40 * * *$ & $.25 * * *$ & $.14 * *$ & $.22 * * *$ \\
\hline 4. Discrediting & & & - & $.82 * * *$ & $.65 * * *$ & $.57 * * *$ & $.31 * * *$ & $.41 * * *$ \\
\hline 5. Affective indifference & & & & - & $.62 * * *$ & $.52 * * *$ & $.24 * * *$ & $.38 * * *$ \\
\hline 6. Threats & & & & & - & $.72 * * *$ & $.49 * * *$ & $.62 * * *$ \\
\hline 7. Emotional manipulation & & & & & & - & $.48 * * *$ & $.51 * * *$ \\
\hline 8. Domination & & & & & & & - & $.62 * * *$ \\
\hline 9. Physical violence & & & & & & & & - \\
\hline
\end{tabular}

Note. $N=500 . * p<.05 . * * p<.01 . * * * p<.001$. 
Table showed that viewer's reactivity of entertainment correlated negatively to their perception of control, discrediting, affective indifference, and threats. The second subscale of viewer's reactivity i.e., empathy positively correlated with discrediting, threat, emotional manipulation, domination, physical violence, and personal involvement. Subscales of viewer's reactivity and perception of violence against women correlated with one another. So, the first hypothesis was accepted.

Furthermore, t-test was computed to identify the gender differences on the viewer's reactivity towards drama scenes presenting violence against women and perception of violence against women. Table 4 provided an overview of the independent sample t-test for gender difference on the study variables.

Table 4

Independent Sample t-test for Gender difference in Study Variables $(\mathbf{N}=\mathbf{5 0 0})$

\begin{tabular}{lllllllll}
\hline & \multicolumn{2}{l}{ Men $(\mathrm{n}=233)$} & \multicolumn{3}{c}{ Women $(\mathrm{n}=267)$} & \multicolumn{3}{c}{$95 \% C I$} \\
Variables & $M$ & $S D$ & $M$ & $S D$ & $t(498)$ & $p$ & $L L$ & $U L$ \\
\hline Entertainment & 1.34 & 1.04 & 1.18 & 0.97 & 1.70 & .09 & -.02 & .33 \\
Empathy & 2.60 & 1.08 & 2.60 & 1.06 & 0.06 & .95 & -.18 & .19 \\
Control & 1.88 & 1.08 & 1.78 & 1.06 & 0.96 & .34 & -.10 & .28 \\
Discrediting & 2.91 & 1.00 & 3.04 & 0.91 & -1.49 & .14 & -.30 & .04 \\
Affective indifference & 2.92 & 1.15 & 3.04 & 1.10 & -1.19 & .23 & -.32 & .08 \\
Threats & 2.96 & 0.96 & 2.99 & 0.96 & -0.36 & .72 & -.20 & .14 \\
Emotional manipulation & 2.87 & 1.28 & 2.92 & 1.30 & -0.42 & .68 & -.28 & .18 \\
Domination & 3.09 & 1.23 & 2.84 & 1.37 & 2.16 & .03 & .02 & .48 \\
Physical violence & 3.09 & 1.14 & 3.05 & 1.16 & 0.44 & .66 & -.16 & .25 \\
\hline
\end{tabular}

Table 4 presented the findings of independent sample for gender of the participants on viewer's reactivity and perception of violence against women. The analysis indicated that although both of the groups reported on different sub dimensions of perception of violence against women higher than the average score (except for entertainment and control). However, the gender differences were significant for only on the sub dimensions of perception which is the domination. The findings indicated that women perceive domination as an act of violence more than men.

\section{Discussion}

The primary aim of the present study was to explore the role of viewer's reactivity in the perception of violence against women among viewers of Lahore. The study collected data from 500 viewers of the selected 30 dramas which presented violence against women. However, a secondary aim was to identify the impact of gender on viewer's reactivity and perception of violence against women. Overall, the findings indicated that the viewer's reactivity is associated with their perception of violence against women in real life situations. However, no differences were found on the basis of gender on reactivity and perception of violence against women (except for a subscale of perception; domination). The detailed interpretation of the findings is presented below.

Descriptive statistics of instruments indicated that the mean score viewer's reactivity of empathy and perceived violence against women (except control) were above scale midpoint. This indicated that viewer feel empathetic for the female victim of violence in the dramas and may perceive violence against women in the real life as an act of violence. These findings indicated that general population 
is aware of the impact of violence against women on their individual as well as on their collective life. Similar findings were observed in a study by El Abani and Pourmehdi (2017) who explored the perception of violence against women among Libyan migrants specifically considering domestic violence. They found that ninety five percent that husband's aggressive acts, shouting, pushing etc. are the act of domestic violence against women. This perception about occurrence of violence against women is not solely an agenda and issue of collectivistic culture. However, a study of European Union also found the similar results about perception of domestic violence against women (Eurobarometer, 2016).

However, the gender parity index (World Economic Forum, 2021) indicated reverse. The reason might be that most often violence that women experience in Pakistan is domestic violence which is considered as a private matter and families may handle such issues within them. Most often the parents of daughters desires to resolve the issue and may bring back their daughter to her husband's house only on few words of apology. The main aim of them is to continue the marital bounding resultantly; she may live in such injurious environment for all her life. Important and stronger mechanisms of social control in such situations emerged at that time are the family honour and shame. These may create hindrance in the identification as well as reporting of such violence acts.

Violence against women strongly influenced from the underlying cultural beliefs and the differences in power and control exercised by men; claim of psychosocial theories (Expósito \& Moya, 2005). Around the globe, irrespective to culture and society, the most primary cause of female subordination is patriarchy (Walby, 1990). According to Korac (2018), the patriarchal buildings of the states inherently promote despotic gender systems by constructing the gender role of men as "protectors", and "heroic".

In a similar manner, research found that the perpetrator had specific abilities or supporting mechanisms that aid him for violence against women. An earlier study found of Expósito and Herrera (2009) found that people perceive male perpetrators as hyper masculine than the other male. Hyper masculinity means the perpetrators have feminine features and greater self-esteem. Moreover, greater physical and psychological strengths; control of economy, decision-taking and social resources; as well as fewer social obligations and sexist ideology are the other factors associated with violence against women (Herrera, 2005).

Furthermore, the present findings (of hypothesis 1) established the association of viewer's reactivity and perception of violence against women. The Present age is the age of the media and the present findings can be interpreted as the influence of media. As, the research across the globe highlighted that media influences the perception, attitude, and behaviors of the people (Emmers-Sommer et al., 2006; Fanti et al., 2009; Huesmann \& Kirwil, 2007; Kahlor \& Eastin, 2011; Lee et al., 2017; Lievore, 2003; Wright \& Tokunaga, 2016). More specifically, Easteal, Holland, and Judd (2015) investigated the power of the media to transform public opinion about violence against women. They concluded that the media frames violence that could impede and delay feminist aims of protecting women from violence and improving access to justice. Exposure to the scenes of violence affects actual violence by developing and reinforcing social attitudes that match such behavior (Kahlor \& Eastin, 2011). The findings were also supported by an indigenous study of Roshan and Pervaz (2012) who found the association of exposure of PTV dramas with youth knowledge and attitude of verbal violence. Another study found that around $50 \%$ knowledge of university students related to violence-based situations comes through media (TV, radio and press; Osuna-Rodríguez, Rodríguez-Osuna , Dios , \&Amor, 2020).

Analysis of gender for the reactivity and perception of violence against women indicated that both group rated higher on the subscales (exception for entertainment and control). However, the differences were found only for the domination subscale on which female perceive violence against women as an act of violence more than men. The findings can be interpreted in the cultural context 
of Pakistan where all the main decision of family are under the control of male and the female have a subordinate role in this regard. The Aurat march and gender equality campaigns in Pakistan mainly focused to overthrow the suppression of female by male. The non-significant differences are important with regards to the viewers that may not differ on their reactivity and perception, however, the differences may be found among the general population.

Literature also guided that the inequality between men and women is actually based upon the perceptual supremacy of one gender over the other gender which evident the power game. The model of Pratto and Walker (2004) known as "The bases of gendered power" explained the power as a primary aspect of relationship between men and women. This power is built upon four essential pillars namely; strength/threat, resource's control, social obligations, and ideology. More precisely, men have greater physical strengths due to their masculinity. Access to resources including the basic one differs with respect to gender (e.g., wage of an employee). The women have to perform the role of obligation, and care about others, thus, limiting their prospects to gain power. Lastly, the belief system or ideology in the culture explained the difference of power with respect to gender.

\section{Conclusion}

Overall, the results point towards viewer's reactivity of empathy and perception of violence against women as an act of violence as opposed to normal practice. This means that the viewers of Lahore have the viewed that violence against women is the root cause of many other issues in the society. Moreover, the results also concluded that among the different dimensions of reactivity and perception of violence against women, women perceive domination of men as an act of violence and considered it as a punishable act. Cultural of Pakistan supports the power and domination of male and subordination of female in this regards. This aspect is also heighted by global gender gap report. Certainly, the society that desires to be representative and democratic must admire and promote human rights (Amorós, 2008) and consequently give no room to violence/ discrimination/ aggression against women due to their gender. Therefore, keeping in view the present findings and existing literature, the sources of socializations such as the content of media must be closely assessed and presented to impact positively in society at large.

\section{Strengths and Limitations}

The study is first of its kind to measure reactivity of viewer with respect to their perception of violence against women. It has few limitations that are presented here along with a suggestion for future research. The sample was taken only from Lahore, so, the findings cannot be generalized for all of the Pakistani population. The role of reactivity of viewers in their perception of violence against women was explored using cross-sectional design which limits the causation inferences; therefore, in future experimental design can be used to infer causation. Lastly, although present research explored the relation of viewer' reactivity and perception of violence against women, however, it is also important tosee the behavioral changes of viewers.

\section{Implications}

Violence against women is a common issue of both developed and developing countries and women of all socio-economic backgrounds may affect by this violence. Therefore, there is a dire need to consider this issue from the micro-level of the family to the macro-level of the global world. Chomsky (2002) mentioned in his book that governments spend billions of dollars every year just to control the public minds. The study implicates that government should invest in media to change the perception of violence against women thus may control the incidents of violence against women in real life. Moreover, a community-based, multi-pronged approach and sustained engagement with multiple stakeholders should be done to decrease violence against women. The most effective initiatives address underlying risk factors for violence, including social norms regarding gender roles and the acceptability of violence. 
The findings highlighted that perception of violence against women as an act of violence. So, it may be improved furthermore to change these act of violence in real life situations. In line with the social learning theory of Bandura narrates that acceptance and action of violence both are conditioned through learning. As per the social cognitive theory, the environment has a strong influence on personal attitude and behavior (Bandura, 2002, 2004), similar is found in the present study for reactivity of viewers and their perception. This implicate that the perceptions can be modified and shaped through the appropriate use of media as individuals may even imitate the behaviors of the characters they see on the television. They are likely to emulate certain characters who are praised for their behaviors (Lee et al., 2011).

\section{References}

Abraham, M. (2000). Speaking the unspeakable. New Brunswick, NJ: Rutgers University Press.

Amorós, C. (2008). Women and Imaginary of Globalization; Homo Sapiens Ediciones: Sarmiento, Argentina.

Ayyub, R. (2000). Domestic violence in the South Asian Muslim immigrant population in the United States. Journal of Social Distress and Homeless, 9, 237-248.

Bandura, A. (2002). Social cognitive theory in cultural context. Applied psychology, 51(2), 269-290.

Bandura, A. (2004). Health promotion by social cognitive means. Health education \& behavior, 31(2), 143-164.

Bettencourt A. (2000). Violence against women in Pakistan. Human Rights Advocacy Clinic; $\begin{array}{lllll}\text { Litigation } & \text { Report } & \text { Spring } & \text { Retrieved } & \text { from }\end{array}$ www.du.edu/intl/humanrights/violencepkstn.pdf

Bloom, S. S. (2008). Violence against women and girls: A compendium of monitoring and evaluation indicators. MEASURE Evaluation, Carolina Population Center.

Díaz-Aguado, M .J. (2003). Adolescencia, sexismo y violencia de género. Papeles del Psicólogo, 84, 35-44.

Cantera, I., Estébanez, I., i Vázquez, N. (2009): Violencia contra las mujeres jóvenes: la violencia psicológica en las relaciones de noviazgo. Bilbao: Servicio de Mujer del Módulo Psicosocial de Deusto-San Ignacio, Emakunde. Recuperat de http:// minoviomecontrola.com/ianireestebanez/ Resumen-violencia-contra- mujeres-jovenes-noviazgo.pdf

Chomsky, N. (2002). Media control: The spectacular achievements of propaganda (Vol. 7). Seven Stories Press.

Council of Europe. (2011). Council of Europe Convention on preventing and combating violence against women and domestic violence. Retrieved on November 22, 2014 from http://conventions.coe.int/Treaty/EN/Reports/Html/210.htm

Cuklanz, L. M. (2000). Rape on prime time: Television, masculinity, and sexual violence. Philadelphia, PA: University of Pennsylvania Press.

Easteal, P., Holland, K., \& Judd, K. (2015, January). Enduring themes and silences in media portrayals of violence against women. In Women's Studies International Forum (Vol. 48, pp. 103-113). Pergamon.

El Abani, S., \& Pourmehdi, M. (2017). Perception of Domestic Violence against Women amongst Libyan Migrants in Manchester. Journal of Sociology and Social Work, 5(2), 128-138.

Emmers-Sommer, T. M., Pauley, P., Hanzal, A., \& Triplett, L. (2006). Love, suspense, sex, and violence: Men's and women's film predilections, exposure to sexually violent media, and their relationship to rape myth acceptance. Sex Roles, 55(5-6), 311-320.

Estébanez, I., \& Vázquez, N. (2010). Diagnóstico de la percepción y opiniones sobre la violencia sexista de la juventud de los municipios de Ondarroa y Markina-Xemein. Bilbao: Sortzen Consultoría. Recuperado de http://bit. ly/2ko9jfc.

Eurobarometer (2016).Gender based violence. Retrieved from http://www.google.co.uk/url?sa=t\&rct=j\&q=\&esrc=s\&source=web\&cd=2\&ved=0ahUKEwjZtKmU 
7vjQAhVBllQKHbOmDV0QFggnMAE\&url=http\%3A\%2F\%2Fec.europa.eu\%2FCOMMFr ontOffice\%2Fpublicopinion\%2Findex.cfm\%2FResultDoc\%2Fdownload\%2FDocumentKy \%2F75837\&usg=AFQjCNFFLb_FaVPfugVk_A8RQWZGkSprRQ. [Accessed 16 December 2016].

Expósito, F., \& Moya, M. (2005). Violencia de género. In F. Expósito, \& M. Moya (Eds.), Aplicando la psicología social (pp. 201-227). Madrid: Pirámide

Exposito, F., \& Herrera, I. (2009). Social perception of violence against women: individual and psychosocial characteristics of victims and abusers. European journal of psychology applied to legal context, 1(1), 123-145.

Fanti, K. A., Vanman, E., Henrich, C. C., \& Avraamides, M. N. (2009). Desensitization to media violence over a short period of time. Aggressive Behavior: Official Journal of the International Society for Research on Aggression, 35(2), 179-187.

Fikree, F.F., Bhatti, L. I. (1999). Domestic violence and health of Pakistani women. International J Gynaecol Obstet, 65,195-201.

Fikree, F. F., Razzak, J. A., \& Durocher, J. (2005). Attitudes of Pakistani men to domestic violence; A study from Karachi, Pakistan. Journal of Men's Health and Gender, 2(1), 49-58.

Flood, M., \& Pease, B. (2009). Factors influencing attitudes to violence against women. Trauma, violence, $\&$ abuse, 10(2), 125-142.

Hafeez, M. M., Ahmed, R. N., Khan, M. D., \& Safdar, M. A. (2020). What are the Crisis and Issues of Governance in Pakistan? An Analysis. Review of Applied Management \& Social Science, 3(1), 53-59.

Harris, R. J., Firestone, J. M., \& Vega, W. A. (2005). The interaction of country of origin, acculturation, and gender role ideology on wife abuse. Social Science Quarterly, 86(2), 463483.

Herrera, M. C. (2005). Asimetría de poder en las relaciones interpersonales como predictor de la violencia de género. Unpublished manuscript, Universidad de Granada, Spain.

Huesmann, L. R., \& Kirwil, L. (2007). Why observing violence increases the risk of violent behavior by the observer.

Human Rights Commission of Pakistan (HRCP).State of human rights in 1999. Lahore: HRCP, 2000.

Human Rights Watch, 'Crime or Custom? Violence against Women in Pakistan, Report of Human Rights Watch 1999. Retrieved from http://www.hrw.org/reports/1999/pakistan/index.htm

Jamieson, P. E., \& Romer, D. (2014). Violence in Popular U.S. Prime Time TV Dramas and the Cultivation of Fear: A Time Series Analysis.Media and Communication, 2 (2), 31-41. Retrieved from http://repository.upenn.edu/asc_papers/349

Jejeebhoy S. (1998). Associations between wife beating and fetal and infant death: Impressions from a survey in rural India. Stud Fam Plann,29, 300-308.

Kahlor, L., \& Eastin, M. S. (2011). Television's role in the culture of violence toward women: A study of television viewing and the cultivation of rape myth acceptance in the United States. Journal of Broadcasting \& Electronic Media, 55(2), 215-231.

Korac, M. (2018). Feminists against sexual violence in war: The question of perpetrators and victims revisited. Soc. Sci. 7, 182.

Lee, M. J., Hust, S., Zhang, L., \& Zhang, Y. (2011). Effects of violence against women in popular crime dramas on viewers' attitudes related to sexual violence. Mass Communication \& Society, 14(1), 25-44. doi: 10.1080/15205430903531440

Lee, S. K., Lindsey, N. J., \& Kim, K. S. (2017). The effects of news consumption via social media and news information overload on perceptions of journalistic norms and practices. Computers in Human Behavior, 75, 254-263.

Lievore D. (2003). Non-reporting and hidden recording of sexual assault: An international literature review. Canberra: Commonwealth Office of the Status of Women

Linz D, Donnerstein E, Penrod S. 1984. The effects of long-term exposure to filmed violence against 
women. J Commun, 34, 130-147.

Mahlstedt, D. L., \& Welsh, L. A. (2005). Perceived causes of physical assault in heterosexual dating relationships. Violence against women, 11, 447-472.

Mapi Research Institute. (2002). Mapi guidelines for translation. Retrieved from https://linkssystem.org/score/Portal/Moz/PedsQL/PedsQL\%20Linguistic\%20Validation\%20 Guidelines_updated_sept\%202006_cay.pdf

Margolis, D. N. (1998). Culturally sanctioned violence against women: A look at attitudes toward rape. Boston College.

Murnen, S.K., Wright, C., \& Kaluzny, G. (2002). If "boys will be boys", then girls will be victims? A meta-analytic review of the research that relates masculine ideology to sexual aggression. Sex Roles, 46, 359-375.

Osuna-Rodríguez, M., Rodríguez-Osuna, L. M., Dios, I., \& Amor, M. I. (2020). Perception of genderbased violence and sexual harassment in university students: Analysis of the information sources and risk within a relationship. International journal of environmental research and public health, 17(11), 3754.

Pratto, F., \& Walker, A. (2004). The bases of gendered power. In A. H. Eagly, A. E. Beall, \& R. J. Sternberg (Eds.), The psychology of gender (2nd ed., pp. 242-268). New York: The Guilford Press.

Roshan, R. P. M. A., \& Parvez, D. M. A. (2012). Effects hierarchy of violence against women on gender's behavior by the exposure of television fare. Journal of social sciences and management, 2(1), 80-86.

Safdar, F., \& Khan, N. (2020). Stigma, Cognitive Emotional Regulation and Psychological Distress in Victims of Women Trafficking. Bahria Journal of Professional Psychology, 19(2), 75-87.

Shah, S. (July 28, 2021). An overview of crime against women in Pakistan. The News. Retrieved from https://www.thenews.com.pk/print/869740-an-overview-of-crimes-against-women-inpakistan

The Global Gender Gap Report 2021. World Economic Forum 2021. https://www.weforum.org/reports/global-gender-gap-report-2021.

Visaria L. (1999). Violence against women in India: Evidence from rural Gujarat. Domestic violence in India; A summary report of three studies. Washington, DC: International Center for Research on Women (ICRW), pp 14-25.

Walby, S. (1990). Theorising Patriarchy. Oxford: Basil Black Well.

Wear, D. \& Skillicorn, J. H. (2009). In Plain Sight: The Formal, Informal, and Hidden Curricula of a Psychiatry Clerkship. The Educational Environment Academic Medicine, 84(4).

White, J. W. (2001). Aggression and gender. In Encyclopedia of women and gender (Vol. 1, pp. 8193): New York: Academic Press.

World bank (2019, September 25). Gender-Based Violence (Violence Against Women and Girls). Retrieved from https://www.worldbank.org/en/topic/socialsustainability/brief/violenceagainst-women-and-girls

Wright, P. J., \& Tokunaga, R. S. (2016). Men's objectifying media consumption, objectification of women, and attitudes supportive of violence against women. Archives of Sexual Behavior, 45(4), 955-964.

World Health Organization. (2021, March9). Violence against women. Retrieved from https://www.who.int/news-room/fact-sheets/detail/violence-against-women

Zakar, R., Zakar, M. Z., \& Kraemer, A. (2013). Men's beliefs and attitudes toward intimate partner violence against women in Pakistan. Violence against women, 19(2), 246-268. 